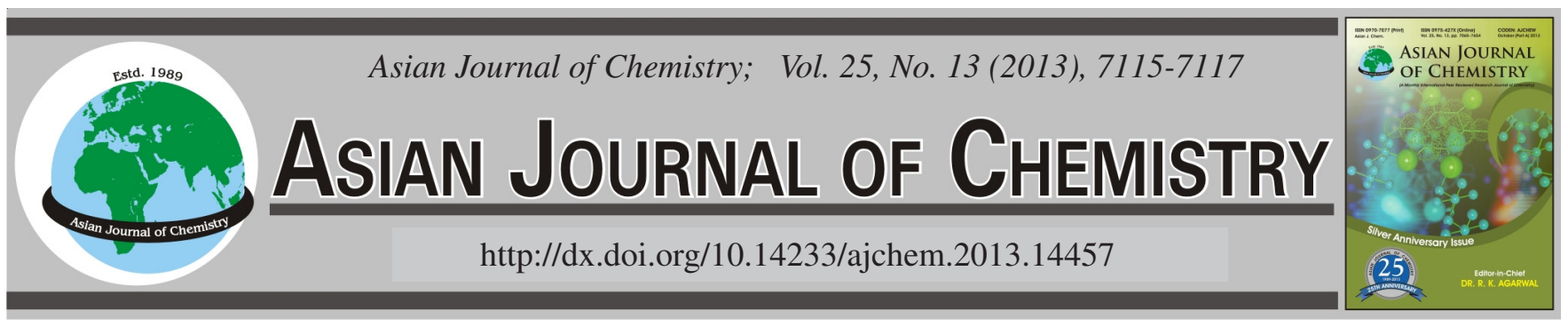

\title{
Synthesis and Crystal Structure of a New \\ 2D-Supramolecular Complex: $\left[\mathrm{Cd}\left(\mathrm{C}_{17} \mathrm{H}_{13} \mathrm{~N}_{2} \mathrm{O}_{2}\right)_{2}\left(\mathrm{C}_{2} \mathrm{H}_{6} \mathrm{O}\right)_{2}\right]$
}

Yin-XIA Sun ${ }^{*}$, Rui-e Lu, Qing-Ying Lan, XIAO-Yan Zhang and Fei-XIA Ma

School of Chemical and Biological Engineering, Lanzhou Jiaotong University, Lanzhou 730070, P.R. China

*Corresponding author: E-mail: sun_yinxia@163.com

(Received: 20 August 2012;

Accepted: 14 June 2013)

AJC-13653

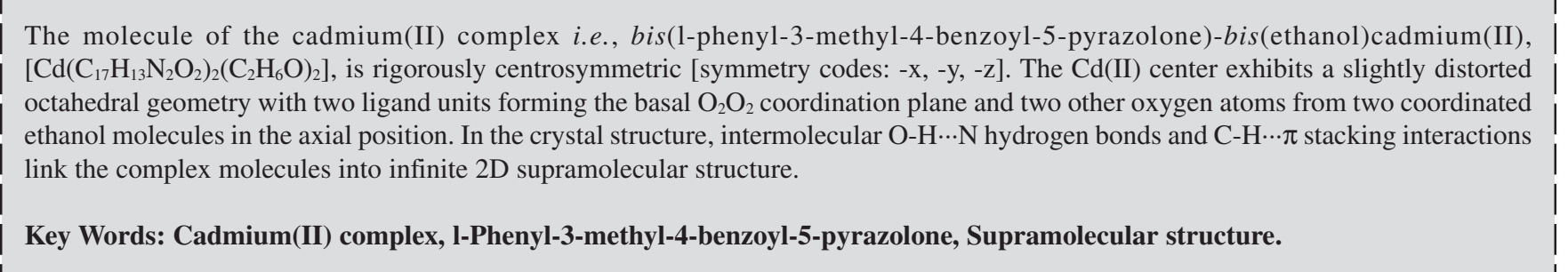

\section{INTRODUCTION}

1-Phenyl-3-methyl-4-benzoyl-5-pyrazolone was known to possess a high chelating ability with the metal ions and high pharmaceutical, biological, clinical and analytical activities $^{1-3}$. It existed as two forms: the enol form and the keto form ${ }^{4}$. When it coordinated with metal ions, the complexes showed various structures such as facial (fac-) and meridional (mer-) forms ${ }^{5,6}$. As an extension of our research work ${ }^{7,8}$ on the structural characterization of transition metal complexes, a single crystal of Cd(II) complex, bis(1-phenyl-3-methyl-4-benzoyl5-pyrazolone)bis(ethanol)cadmium(II) was obtained and structurally characterized by X-ray crystallography.

\section{EXPERIMENTAL}

1-Phenyl-3-methyl-4-benzoyl-5-pyrazolone was purchased from Alfa Aesar was used without further purification. The other reagents and solvents were analytical grade reagents from Tianjin Chemical Reagent Factory. C, H and N analyses were carried out with a GmbH VariuoEL V3.00 automatic elemental analyzer. X-ray single crystal structure was determined on a Bruker Smart 1000 CCD area detector.

General procedure: The ligand 1-phenyl-3-methyl-4benzoyl-5-pyrazolone $(0.01 \mathrm{mmol})$ was dissloved in an anhydrous EtOH solution ( $5 \mathrm{~mL}$ ) then added dropwise to the same solvent $(2 \mathrm{~mL})$ of cadmium(II) acetate hydrate $(0.01$ $\mathrm{mmol})$. Then the mixture was stirred and refluxed at $428 \mathrm{~K}$ for $6 \mathrm{~h}$. The resulting solution was then filtered and the filtrate was kept in air for 2 weeks at room temperature. Colourless block-like single crystals of $\mathrm{Cd}(\mathrm{II})$ complex suitable for $\mathrm{X}$-ray crystallographic analysis was obtained. Anal. calcd. (\%) for $\mathrm{C}_{38} \mathrm{H}_{38} \mathrm{~N}_{4} \mathrm{O}_{6} \mathrm{Cd}$ : C, 60.12; H, 5.05; N, 7.38; Cd, 14.81. Found (\%): C, 60.23; H, 5.01; N, 7.16; Cd, 14.95 .

X-Ray structure determination: The single crystal of the title complex, with approximate dimensions of $0.47 \mathrm{~mm} \times$ $0.35 \mathrm{~mm} \times 0.23 \mathrm{~mm}$ was placed on a Bruker Smart 1000 diffractmeter equipped with Apex CCD area detector. The diffraction data were collected using a graphite monochromated $\operatorname{MoK}_{\alpha}$ radition $(\lambda=0.71073 \AA$ ) at $298(2) \mathrm{K}$. The structure was solved by using the program SHELXS-97 ${ }^{9}$ and Fourier difference techniques and refined by full-matrix least-squares method on $\mathrm{F}^{2}$ using SHELXL- $97^{10}$. Details of the data collection and refinements of Cd(II) complex are given in Table-1. The non-hydrogen atoms were refined anisotropically. Hydrogen atoms were added theoretically.

\section{RESULTS AND DISCUSSION}

The X-ray crystallography indicates that the crystal structure of $\mathrm{Cd}(\mathrm{II})$ complex is built up only by $\mathrm{C}_{38} \mathrm{H}_{38} \mathrm{~N}_{4} \mathrm{O}_{6} \mathrm{Cd}$ molecules (Fig. 1), in which all bond lengths are in normal ranges. The $\mathrm{Cd}$ (II) center is located in the centre of the equatorial plane defined by the two oxygen atoms (O1 and $\left.\mathrm{O} 1^{\# 1}\right)$ in enol-form from pyrazolone ring and the two carbonyl oxygen atoms $\left(\mathrm{O} 2\right.$ and $\left.\mathrm{O} 2^{\# 1}\right)$ and the other two oxygen atoms $(\mathrm{O} 3$ and $\mathrm{O}^{\# 1}$ ) from two coordinated ethanol molecules lie in the axial position of the coordination plane. Thus, the six oxygen donors construct an octahedral geometry around $\mathrm{Cd}(\mathrm{II})$ atom. The 


\begin{tabular}{ll}
\hline \multicolumn{1}{c}{ CRYSTAL DATA AND REFINEMENT } \\
\multicolumn{1}{c}{ PARAMETERS FOR THE Cd(II) COMPLEX } \\
\hline Empirical formula & $\mathrm{C}_{38} \mathrm{H}_{38} \mathrm{~N}_{4} \mathrm{O}_{6} \mathrm{Cd}$ \\
Formula weight & 759.12 \\
Temperature & $298(2) \mathrm{K}$ \\
Wavelength & $0.71073 \AA$ \\
Crystal system & Triclinic \\
Space group & $\mathrm{P}-1$ \\
Cell dimensions & $\mathrm{a}=9.1410(10) \AA, \mathrm{b}=10.3201(13) \AA$ \\
& $\mathrm{c}=10.9079(14) \AA, \alpha=106.7810^{\circ}, \beta=$ \\
& $107.613(2)^{\circ}, \gamma=104.6090^{\circ}$ \\
Volume & $871.56(18) \AA^{3}$ \\
$\mathrm{Z}$ & 1 \\
Density (calculated) & $1.446 \mathrm{mg} / \mathrm{m}^{3}$ \\
Absorption coefficient & $0.679 \mathrm{~mm}^{-1}$ \\
$\mathrm{~F}_{(000)}$ & 390 \\
Index ranges & $-10 \leq \mathrm{h} \leq 10,-10 \leq \mathrm{k} \leq 12,-12 \leq 1 \leq 12$ \\
Reflections collected/unique & $4530 / 3015\left[\mathrm{R}_{\text {int }}=0.0203\right]$ \\
Data/restraints/parameters & $3015 / 0 / 245$ \\
Goodness-of-fit on $\mathrm{F}^{2}$ & 1.075 \\
Final $\mathrm{R}$ indices [I $>2 \sigma(\mathrm{I})]$ & $\mathrm{R}_{1}=0.0345, \mathrm{wR}_{2}=0.0780$ \\
$\mathrm{R}$ indices (all data) & $\mathrm{R}_{1}=0.0399, \mathrm{wR} \mathrm{R}_{2}=0.0827$ \\
Largest diff. peak and hole & 0.447 and $-0.362 \mathrm{e} . \AA$ \\
\hline &
\end{tabular}

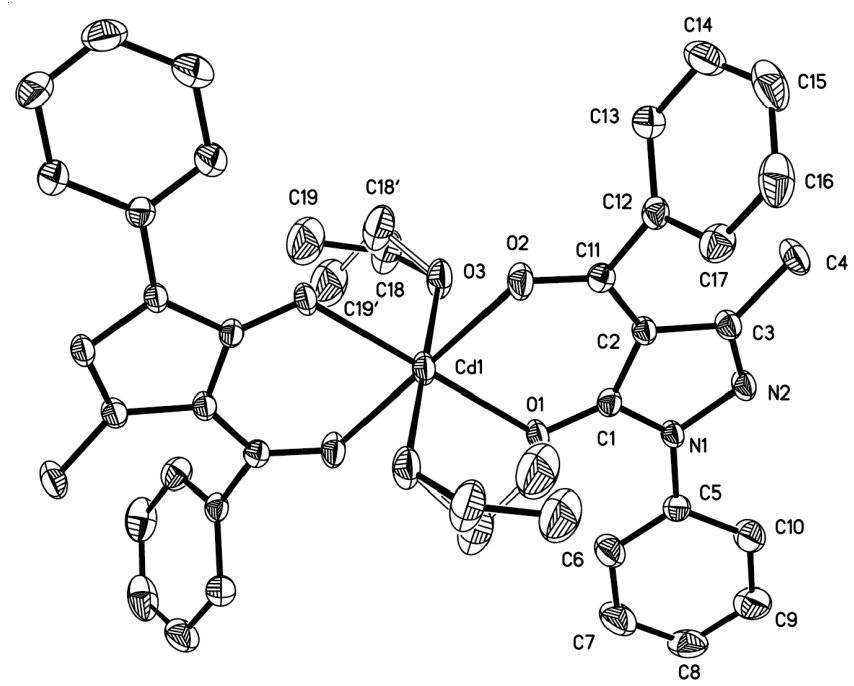

Fig. 1. Molecule structure of the Cd(II) complex

distance of $\mathrm{O} 1-\mathrm{Cd} 1\left(\mathrm{O} 1^{\# 1}-\mathrm{Cd} 1\right), \mathrm{O} 2-\mathrm{Cd} 1\left(\mathrm{O} 2^{\# 1}-\mathrm{Cd} 1\right)$ and $\mathrm{O} 3-$ $\mathrm{Cd} 1\left(\mathrm{O}^{\# 1}-\mathrm{Cd} 1\right)$ is $2.226,2.280$ and $2.345 \AA$, respectively (Table-2), so the coordination sphere of $\mathrm{Cd}(\mathrm{II})$ complex can be described as an elongate octahedron geometry. Moreover, the whole $\mathrm{Cd}(\mathrm{II})$ complex is rigorously centrosymmetric [symmetry codes: -x, -y, -z] and Cd(II) atom lies in the crystallographic inversion center. In the crystal, the complex molecules

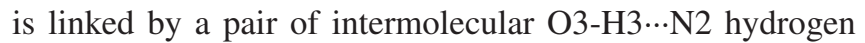
bonds into a 1D infinite chain parallel to the a-axis (Fig. 2). This linkage is further stabilized by a pair of intermolecular C9-H9 ... $\pi(\mathrm{C} 12-\mathrm{C} 17)$ hydrogen bonds interactions to form the other 1D infinite chain (Fig. 3). Thus, every complex molecule links four other molecules into an infinite 2D-layer supramolecular structure via intermolecular $\mathrm{O}-\mathrm{H} \cdots \mathrm{N}$ and $\mathrm{C}-\mathrm{H} \cdots \pi$ hydrogen-bonding interactions.

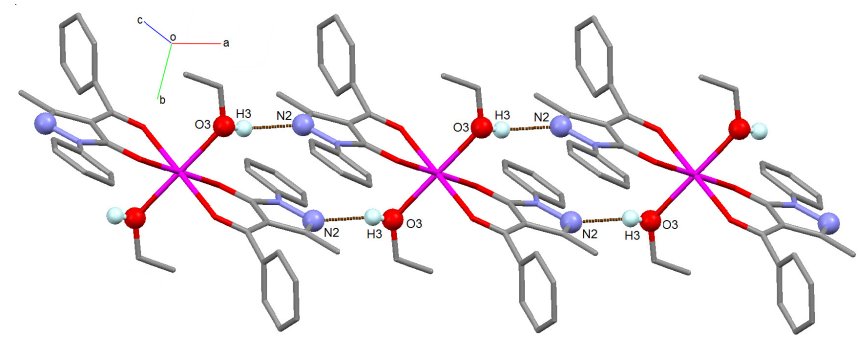

Fig. 2. View of the $1 \mathrm{D}$ chain along a-axis linked by $\mathrm{O} 3-\mathrm{H} 3 \cdots \mathrm{N} 2$ hydrogen bonds

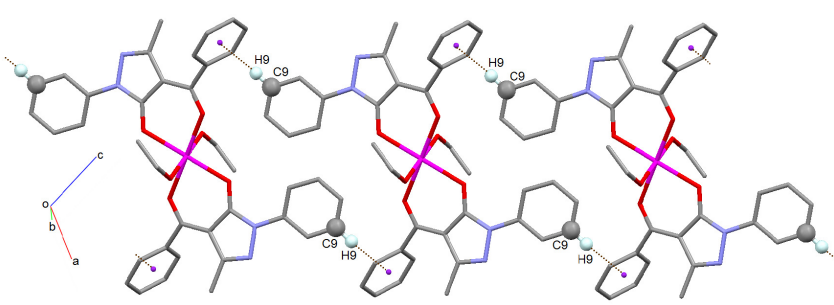

Fig. 3. View of the $1 \mathrm{D}$ chain linked by $\mathrm{C} 9-\mathrm{H} 9 \cdots \mathrm{p}(\mathrm{C} 12-\mathrm{C} 17)$ hydrogen bonds

\begin{tabular}{|c|c|c|c|c|}
\hline \multicolumn{5}{|c|}{$\begin{array}{c}\text { TABLE-3 } \\
\text { HYDROGEN-BONDING DATA }\left[\AA{ }^{\circ},{ }^{\circ}\right]\end{array}$} \\
\hline $\mathrm{D}-\mathrm{H} \cdots \mathrm{A}$ & $\mathrm{d}(\mathrm{D}-\mathrm{H})$ & $\mathrm{d}(\mathrm{H} \cdots \mathrm{A})$ & $\mathrm{d}(\mathrm{D} \cdots \mathrm{A})$ & $\angle \mathrm{D}-\mathrm{H} \cdots \mathrm{A}$ \\
\hline $\mathrm{O} 3-\mathrm{H} 3 \cdots \mathrm{N} 2$ & 0.82 & 2.08 & $2.835(4)$ & 153 \\
\hline C9-H9 $\cdots \mathrm{Cg}^{\mathrm{a}}$ & 0.93 & 2.78 & $3.549(5)$ & 141 \\
\hline
\end{tabular}

\section{ACKNOWLEDGEMENTS}

The authors thank the Young Scholars Science Foundation of Lanzhou Jiaotong University (2011007) for financial support.

TABLE-2

SELECTED BOND LENGTHS $(\AA ̊)$ AND ANGLES $\left({ }^{\circ}\right)$ FOR THE Cd(II) COMPLEX

\begin{tabular}{|c|c|c|c|c|c|}
\hline Bond & Lengths & Bond & Lengths & Bond & Lengths \\
\hline $\mathrm{Cd}_{1-O} \mathrm{O}^{\# 1}$ & $2.2264(2)$ & $\mathrm{Cd} 1-\mathrm{O} 1$ & $2.2264(2)$ & $\mathrm{Cd} 1-\mathrm{O} 2$ & $2.280(2)$ \\
\hline $\mathrm{Cd} 1-\mathrm{O} 2^{\# 1}$ & $2.280(2)$ & $\mathrm{Cd} 1-\mathrm{O} 3$ & $2.345(2)$ & $\mathrm{Cd} 1-\mathrm{O}^{\# 1}$ & $2.345(2)$ \\
\hline Bond & Angles & Bond & Angles & Bond & Angles \\
\hline $\mathrm{O}^{\# 1}-\mathrm{Cd} 1-\mathrm{O} 2$ & $95.95(7)$ & $\mathrm{O} 1-\mathrm{Cd} 1-\mathrm{O} 3$ & $88.92(8)$ & $\mathrm{O} 2^{\# 1}-\mathrm{Cd} 1-\mathrm{O} 3^{\# 1}$ & $86.35(8)$ \\
\hline $\mathrm{O} 1-\mathrm{Cd} 1-\mathrm{O} 2$ & $84.05(7)$ & $\mathrm{O} 2-\mathrm{Cd} 1-\mathrm{O} 3$ & $86.35(8)$ & $\mathrm{O} 3-\mathrm{Cd} 1-\mathrm{O}^{\# 1}$ & $180.00(0)$ \\
\hline $\mathrm{O} 1^{\# 1}-\mathrm{Cd} 1-\mathrm{O} 2^{\# 1}$ & $84.05(7)$ & $\mathrm{O} 22^{\# 1}-\mathrm{Cd} 1-\mathrm{O} 3$ & $93.65(8)$ & C1-O1-Cd1 & $122.41(2)$ \\
\hline $\mathrm{O} 2-\mathrm{Cd} 1-\mathrm{O} 2^{\# 1}$ & $180.00(0)$ & $\mathrm{O} 1-\mathrm{Cd} 1-\mathrm{O} 3^{\# 1}$ & $91.08(8)$ & C18-O3-Cd1 & 133.1(1) \\
\hline C18'-O3-Cd1 & $125.0(1)$ & & & & \\
\hline
\end{tabular}

Symmetry transformations used to generate equivalent atoms: ${ }^{\# 1}-\mathrm{x}+1,-\mathrm{y}+1,-\mathrm{z}+3$. 


\section{REFERENCES}

1. R.C. Maurya, A. Pandey, J. Chaurasia and H. Martin, J. Mol. Struct., 798, 89 (2006)

2. W.K. Dong, J.H. Feng, L. Wang, L. Xu, L. Zhao, X.Q. Yang and T.Z Yu, Transition Met. Chem., 32, 1101 (2007).

3. W.K. Dong, X.Q. Song, Y.X. Sun and H.L. Wu, Chin. J. Inorg. Chem., 23, 1809 (2007).

4. Y. Akama, A. Tong, N. Matsumoto, T. Ikeda and S. Tanaka, Vibrat. Spect., 13, 113 (1996)
5. L. Chen, J. Qiao, L. Duan and Y. Qiu, Synth. Met., 157, 713 (2007).

6. U. Toyotoshi, S. Tadanobu and A. Yoshifumi, J. Mol. Struct., 750, 51 (2005).

7. W.K. Dong and J.H. Feng, Acta Cryst., E62, o3577 (2006).

8. W.K. Dong, X.N. He, H.B. Yan, Z.W. Lv, X. Chen, C.Y. Zhao and X.L. Tang, Polyhedron, 28, 1419 (2009).

9. G.M. Sheldrick, SHELXS97, Program for Crystal Structure Determination, University of Göttingen, Germany (1996).

10. G.M. Sheldrick, Acta Cryst., A64, 112 (2008). 